Original

\title{
Effect of dispersed hydrophilic silicon dioxide nanoparticles on batch adsorption of benzoic acid from aqueous solution using modified natural vermiculite: An equilibrium study
}

\author{
Ehsan Sadeghi Pouya ${ }^{a}$, Hossein Abolghasemi ${ }^{a, b, *}$, Hooman Fatoorehchi ${ }^{a}$, Bettina Rasem ${ }^{c}$, \\ Seyed Jalaledin Hashemi ${ }^{\mathrm{d}}$ \\ ${ }^{a}$ Center for Separation Processes Modeling and Nano-Computations, School of Chemical Engineering, College of Engineering, University of Tehran, P.O. Box \\ 11365-4563, Tehran, Iran \\ ${ }^{\mathrm{b}}$ Oil and Gas Center of Excellence, University of Tehran, Tehran, Iran \\ ${ }^{\mathrm{c}}$ Department of Chemical Engineering, Faculty of Process and Systems Engineering, Technical University of Berlin, Berlin, Germany \\ ${ }^{\mathrm{d}}$ Department of Chemical Engineering, Faculty of Engineering, McGill University, Montreal, Canada \\ Received 10 March 2016; accepted 15 August 2016 \\ Available online 11 October 2016
}

Dedicated to the memory of our dear colleague Prof. Seyed Jalaledin Hashemi, who passed away before the submission of this article.

\begin{abstract}
The equilibrium adsorption of benzoic acid from an aqueous medium on a natural vermiculite-based adsorbent was studied in the presence and absence of hydrophilic silicon dioxide nanoparticles in batchwise mode. The adsorbent was prepared through grinding natural vermiculite in a laboratory vibratory disk mill and the surfactant modification of ground vermiculite by cetyltrimethylammonium bromide, subsequently. The equilibrium isotherm in the presence and absence of nanoparticles was experimentally obtained and the equilibrium data were fitted to the Langmuir, Freundlich, Dubinin-Radushkevich and Temkin models. The results indicated that the dispersion of silicon dioxide nanoparticles at optimum concentration in the liquid phase remarkably increases the removal efficiency. Furthermore, it yields a more favorable equilibrium isotherm and changes the compatibility of equilibrium data from the Langmuir and Temkin equations to just the Langmuir equation. A quadratic polynomial model predicting the equilibrium adsorbent capacity in the presence of nanoparticles as a function of the adsorbate and initial nanoparticle concentrations was successfully developed using the response surface methodology based on the rotatable central composite design. A desirability function was used in order to optimize the values of all variables, independent and dependent ones, simultaneously.

(C) 2016 Universidad Nacional Autónoma de México, Centro de Ciencias Aplicadas y Desarrollo Tecnológico. This is an open access article under the CC BY-NC-ND license (http://creativecommons.org/licenses/by-nc-nd/4.0/).
\end{abstract}

Keywords: Adsorption; Benzoic acid; Vermiculite; Cetyltrimetylammonium bromide; Silicon dioxide nanoparticles; Response surface methodology; Desirability function

\section{Introduction}

The burgeoning trend of industrialization has contributed to the discharge of a great deal of pollutants into our environment. Aromatic carboxylic acids (ACAs) are a sort of organic

\footnotetext{
* Corresponding author.

E-mail addresses: abolghasemi.ha@gmail.com,hoab@ut.ac.ir (H. Abolghasemi).

Peer Review under the responsibility of Universidad Nacional Autónoma de
} México. compounds whose occurrence in industrial waste effluents originates not only from the disposal of finished products and undesirable by-products, but also from the microbial oxidation of hydrocarbons. Because of the poor biodegradability of ACAs arising out of the electron-withdrawing carboxyl group on their phenyl ring, the wastewaters involved must be purified prior to discharge, as recommended by the European Environment Agency (Huang, Wang, \& Huang, 2011; Knepper et al., 1999). Benzoic acid (BA) as the simplest ACA with widespread applications in many industrial sectors can serve as a suitable model compound to make a study of eliminating ACAs 


\begin{tabular}{|c|c|}
\hline \multicolumn{2}{|c|}{ Nomenclature } \\
\hline \multicolumn{2}{|c|}{$a_{0}, a_{i}$ and $a_{i j}$ adjustable parameters of RSM-based model } \\
\hline$A_{T}$ & Temkin isotherm equilibrium constant (L/mg) \\
\hline$b_{T}$ & Temkin isotherm constant $(\mathrm{kJ} / \mathrm{mol})$ \\
\hline$C_{0}$ & initial concentration of BA (mg/L) \\
\hline$C_{e}$ & equilibrium concentration of $\mathrm{BA}(\mathrm{mg} / \mathrm{L})$ \\
\hline$C_{i}$ & initial concentration of nanoparticles $(\mathrm{mg} / \mathrm{L})$ \\
\hline$D$ & overall desirability function \\
\hline$d_{i}$ & individual desirability function \\
\hline & number of manipulated variables \\
\hline$K_{D-R}$ & $\begin{array}{l}\text { Dubinin-Radushkevich } \text { isotherm constant } \\
\left(\mathrm{mol}^{2} / \mathrm{kJ}^{2}\right)\end{array}$ \\
\hline$K_{F}$ & Freundlich isotherm constant $\left((\mathrm{mg} / \mathrm{g})(\mathrm{L} / \mathrm{mg})^{1 / n}\right)$ \\
\hline$K_{L}$ & Langmuir isotherm constant (L/mg) \\
\hline$L_{i}$ & lower limit \\
\hline$M$ & adsorbent mass (g) \\
\hline$N$ & number of data points \\
\hline$n$ & number of variables \\
\hline$n_{0}$ & number of central point replications \\
\hline$n_{F}$ & Freundlich adsorption intensity constant \\
\hline$p, q$ & importance weight \\
\hline$q_{D-R}$ & $\begin{array}{l}\text { Dubinin-Radushkevich adsorption capacity } \\
(\mathrm{mg} / \mathrm{g})\end{array}$ \\
\hline$q_{e}$ & equilibrium adsorption capacity (mg/g) \\
\hline$q_{e, \mathrm{cal}}$ & $\begin{array}{l}\text { calculated adsorption capacity at equilibrium } \\
(\mathrm{mg} / \mathrm{g})\end{array}$ \\
\hline$q_{e, \exp }$ & $\begin{array}{l}\text { experimental adsorption capacity at equilibrium } \\
(\mathrm{mg} / \mathrm{g})\end{array}$ \\
\hline$q_{L}$ & Langmuir adsorption capacity (mg/g) \\
\hline & universal gas constant $(\mathrm{kJ} / \mathrm{mol} \mathrm{K})$ \\
\hline$T$ & temperature $(\mathrm{K})$ \\
\hline$T_{i}$ & target value \\
\hline$U_{i}$ & upper limit \\
\hline$V$ & solution volume $(\mathrm{L})$ \\
\hline$X_{i}$ & coded manipulated variable \\
\hline & uncoded manipulated variable \\
\hline$x_{i, \max }$ & upper level of an uncoded manipulated variable \\
\hline $\begin{array}{l}x_{i, \min } \\
Y\end{array}$ & $\begin{array}{l}\text { lower level of an uncoded manipulated variable } \\
\text { predicted response }\end{array}$ \\
\hline & variable \\
\hline
\end{tabular}

from aquatic media (Giannakas, Antonopoulou, Deligiannakis, \& Konstantinou, 2013).

The conventional processes that have been thus far utilized for removing BA from aqueous solution include photocatalytic degradation (Gandhi et al., 2011), electrochemical oxidation (Garg \& Prasad, 2015), microbial filtration (Zachritz, Lundie, \& Wang, 1996) and adsorption (Xin et al., 2011; Yan et al., 2007; Yıldız, Gönülşen, Koyuncu, \& Çalımlı, 2005). From the practical perspective, the adsorption process is approved as a highly selective, facile and economic in terms of design and operation and recyclable method for the removal of a vast array of organic and inorganic contaminants (Qu, 2008).
Nowadays, natural clay minerals, like vermiculite, because of being inexpensive, abundant and eco-friendly with a high capability for ion exchange, have drawn much attention either as direct adsorbent, for example, heavy metals (Gupta \& Bhattacharyya, 2011) and a variety of dyes (Yagub, Sen, Afroze, \& Ang, 2014), or as host matrices to fabricate effective adsorbents concerning low and high molecular weight organic acid species like BA (Borisover \& Davis, 2015). The modification of clay minerals by substituting their inorganic interlamellar cations with quaternary ammonium cations using cationic surfactants like cetyltrimetylammonium bromide (CTAB) is one of the most common methods to decrease the high degree of hydrophilicity and the high concentration of negative structural charge of clay minerals, thereby improving their performance for the adsorption of organic acids from aqueous solution (Anirudhan \& Ramachandran, 2006; De Araújo Medeiros, Sansiviero, Araújo, \& Lago, 2009; Su, Lin, Wang, Xie, \& Chen, 2011; Xin et al., 2011; Yan et al., 2007; Y1ld1z et al., 2005). There are also reports on the increase of cation exchange capacity, porosity and surface chemical reactivity of clay minerals after grinding by a vibratory disk mill, which favors their susceptibility to be modified organically (Filipović-Petrović, Kostić-Gvozdenović, \& Erić-Antonić, 2002; Hongo, Yoshino, Yamazaki, Yamasaki, \& Satokawa, 2012; Jiménez De Haro et al., 2004).

Over the past decade, the nanotechnology revolution has opened up a promising era in numerous fields of science (Choolaei, Rashidi, Ardjmand, Yadegari, \& Soltanian, 2012) (Banaei, Vojoudi, Karimi, Bahar, \& Pourbasheer, 2015). In this regard, several studies have been recently carried out to increase the efficiency of separation processes like liquid-liquid extraction (Bahmanyar, Khoobi, Mozdianfard, \& Bahmanyar, 2011; Khoobi et al., 2013; Raji-Asadabadi, Abolghasemi, Maragheh, \& Davoodi-Nasab, 2013) and liquid chromatography (Nilsson, Birnbaum, \& Nilsson, 2007; Zhang, Wang, Liao, \& Liu, 2006) in the presence of dispersed nanomaterials (typically nanoparticles). Although these studies are in their infancy, they have shown the potential of nanomaterials as multifunctional components to improve the separation efficiency. All the foregoing studies are focused on the increase of mass transfer in nanofluids. The enhanced mass transfer of several substances in water-based nanofluids in comparison with pure water has been reported by a number of scholars (Ashrafmansouri \& Nasr Esfahany, 2014; Krishnamurthy, Bhattacharya, Phelan, \& Prasher, 2006; Veilleux \& Coulombe, 2011).

To our best knowledge, the present study is one of few investigations on the effect that the dispersion of nanoparticles in the adsorption medium has on the removal efficiency and the adsorbent capacity. In 2010, Jasper et al. (2010) evaluated the effect of dispersed silicon dioxide, titanium dioxide and iron(III) oxide nanoparticles on the batch adsorption of trichloroethylene from contaminated water by activated carbon. They found that silicon dioxide nanoparticles do not have any remarkable effect on the adsorption efficiency whereas the two other nanoparticles remarkably increase the adsorption efficiency. Silicon dioxide nanoparticles are one of the most common nanoparticles by reason of their low cost and commercial availability. The good 
biocompatibility of these nanoparticles makes them applicable to processes dealing with environmental issues (Sun, Yan, Yang, \& Sun, 2006; Sun et al., 2007).

Today, multivariate statistical techniques are favored because they are time and cost efficient for experimentation and because they facilitate probing in the effect of inputs, alone and in combination, on the outputs in a multivariable system. Response surface methodology (RSM) is one of the most useful multivariate statistical techniques, particularly when a few variables are involved. This methodology is on the basis of fitting a polynomial model to a series of experimental data with the aim of making statistical previsions (Bezerra, Santelli, Oliveira, Villar, \& Escaleira, 2008; Jain, Garg, \& Kadirvelu, 2011). Since the most successful development of an RSM-based model is intertwined with the most detailed knowledge of process, an experimental design is essential to ascertain which experiments need to be performed in the experimental region being studied. The central composite design is one of the most standard experimental designs applied for establishing mathematical models estimating the first- and second-order effects in a multivariable system (Montgomery \& Runger, 2010; Murugesan et al., 2014). The application of desirability function approaches in applied and analytical chemistry in order to find the best operating conditions and obtain the best result has attracted much attention in recent years (Bezerra et al., 2008).

In brief, this research is aimed at: (1) optimizing the concentration of dispersed hydrophilic silicon dioxide nanoparticles for the batch adsorption of BA from aqueous solution on mechanically and chemically modified natural vermiculite, (2) comparing the equilibrium isotherm in the presence and absence of nanoparticles, (3) analyzing the equilibrium data by four frequently used isotherm models (the Langmuir, Freundlich, Dubinin-Radushkevich and Temkin models), (4) developing an RSM-based model to study how the initial concentrations of adsorbate and nanoparticles influence the adsorption capacity and, lastly, (5) finding the best local conditions using a desirability function optimization approach.

\section{Materials and methods}

\subsection{Materials}

Natural vermiculite was collected from a mineral deposit in Kaleybar County (East Azerbaijan Province, Iran). BA $\left(\mathrm{C}_{7} \mathrm{H}_{6} \mathrm{O}_{2}\right)$ and $\mathrm{CTAB}\left(\mathrm{C}_{19} \mathrm{H}_{42} \mathrm{BrN}\right)$ of analytical grade were purchased from Merck and Sigma-Aldrich companies. Highly pure hydrophilic silicon dioxide $\left(\mathrm{SiO}_{2}\right)$ nanoparticles were supplied by TECNAN Company. The field emission scanning electron microscopy (FE-SEM) analysis was conducted using a scanning electron microscope (TESCAN, MIRA3 LM) in order to investigate the surface morphology of silicon dioxide nanoparticles. The X-ray diffraction (XRD) analysis was performed using an X-ray diffractometer (PANalytical, X'Pert Pro MPD) in order to investigate the crystalline/amorphous structure of nanoparticles. The inductively coupled plasma mass spectroscopy (ICP-MS) analysis was performed by means of a mass spectrometer (Varian, OES-730) in order to determine the quantitative chemical
Table 1

Some characteristics of the silicon dioxide nanoparticles.

\begin{tabular}{llllll}
\hline Morphology & Purity & $\begin{array}{l}\text { Average } \\
\text { particle } \\
\text { size }\end{array}$ & $\begin{array}{l}\text { BET } \\
\text { surface } \\
\text { area }\end{array}$ & $\begin{array}{l}\text { Total pore } \\
\text { volume }\end{array}$ & $\begin{array}{l}\text { Average } \\
\text { pore } \\
\text { diameter }\end{array}$ \\
\hline Spherical & $>99.9 \%$ & $12.80 \mathrm{~nm}$ & $162.9 \mathrm{~m}^{2} / \mathrm{g}$ & $0.549 \mathrm{~cm}^{3} / \mathrm{g}$ & $11.01 \mathrm{~nm}$ \\
\hline
\end{tabular}

composition of impurities in the sample of silicon dioxide nanoparticles. The dynamic light scattering (DLS) analysis was conducted by means of a dynamic light scattering analyzer (Microtrac, Nanotrac Wave) in order to determine the average particle size and also the size distribution of nanoparticles. The textural characteristics (the BET surface area, the total pore volume and the average pore diameter) of silicon dioxide nanoparticles were obtained by the $\mathrm{N}_{2}$ adsorption/desorption technique at $-196^{\circ} \mathrm{C}$ using a gas adsorption analyzer (BEL Japan, BELSORP-mini II). Some characteristics of the used nanoparticles are listed in Table 1 . The silicon dioxide nanofluid was prepared by dispersing a desired amount of nanoparticles in distilled water using an ultrasonicator at a frequency of $20 \mathrm{kHz}$ for $2 \mathrm{hr}$.

\subsection{Preparation of adsorbent}

Initially, the natural vermiculite was reduced in size with a knife mill, passed through a 120-mesh sieve, and subsequently ground in a vibratory disk mill at $2000 \mathrm{rpm}$ for $10 \mathrm{~min}$. Thereafter, $10 \mathrm{~g}$ of ground vermiculite was gently contacted with $1000 \mathrm{~mL}$ of $23 \mathrm{mM} \mathrm{CTAB}$ solution in a beaker at $60^{\circ} \mathrm{C}$ for $24 \mathrm{~h}$ using a heater/stirrer. Finally, the solid phase was removed by centrifugation, rinsed with enough deionized water until no detection of bromide ions by $0.1 \mathrm{M}$ silver nitrate solution, dried at $60{ }^{\circ} \mathrm{C}$ for $48 \mathrm{~h}$, activated at $120^{\circ} \mathrm{C}$ for $1 \mathrm{~h}$, pulverized in an agate mortar and packed for further use. The characteristics of the resultant adsorbent, hereinafter designated as CTAB-V, has been thoroughly described in our earlier works (Sadeghi Pouya et al., 2015a; Sadeghi Pouya et al., 2015b).

\subsection{Batch adsorption experiments}

In general, the adsorption experiments were conducted by placing an optimum amount of CTAB-V samples into $100-\mathrm{mL}$ Erlenmeyer flasks filled with $50 \mathrm{~mL}$ of BA solutions at an optimum initial $\mathrm{pH}$ value and then shaking the flasks at $200 \mathrm{rpm}$ at a temperature of $30^{\circ} \mathrm{C}$ for $12 \mathrm{~h}$ using a thermostatic shaking incubator. After attaining the equilibrium state, the suspensions were centrifuged at $4000 \mathrm{rpm}$ for $15 \mathrm{~min}$ and the supernatants were spectrophotometrically analyzed for the remaining BA concentration at a $\lambda_{\max }$ of $227 \mathrm{~nm}$ (corresponding to the maximum absorbance) using a Unico UV-2100 UV/vis spectrophotometer. Our preliminary experiments demonstrated that in the studied range of BA and nanoparticles initial concentrations, the optimum adsorbent dosage is $0.5 \mathrm{~g} / 50 \mathrm{~mL}$ and the initial solution $\mathrm{pH}$ is optimum when not adjusted (i.e. the initial solution $\mathrm{pH}$ of $3.5 \pm 0.1$ ). The upper and lower limit of BA and nanoparticles initial concentrations was also chosen as $100-1000 \mathrm{mg} / \mathrm{L}$ and 
$1-10 \mathrm{mg} / \mathrm{L}$, respectively. The removal efficiency of BA and the adsorption capacity of CTAB-V at equilibrium were calculated by Eqs. (1) and (2):

Equilibrium removal efficiency $(\%)=\frac{C_{0}-C_{e}}{C_{e}} \times 100$,

$q_{e}=\frac{\left(C_{0}-C_{e}\right) V}{M}$,

where $C_{0}$ is the initial concentration of $\mathrm{BA} ; C_{e}$ is the equilibrium concentration of BA; $q_{e}$ is the equilibrium adsorption capacity; $V$ is the solution volume; $M$ is the adsorbent mass.

\subsection{RSM modeling approach}

To explore an RSM-based correlation between the equilibrium adsorption capacity of CTAB-V in the presence of nanoparticles (as predicted response) and the initial concentrations of BA and nanoparticles (as manipulated variables), the design-expert software package (v. 7.0.0) was employed. A rotatable central composite design was implemented to create an experimental framework totally consisting of 13 runs, as calculated by the expression of $2^{n}+2 n+n_{0}$ using five central point replications that is the software default value for a system with two manipulated variables (Arulkumar, Sathishkumar, \& Palvannan, 2011; Cho \& Zoh, 2007). Given that the manipulated variables in this study were too different in scale, they were normalized in advance of modeling. In this regard, the upper level was coded as +1 , the center level as 0 and the lower level as -1 . For any value that lies either between the lower limit and the center level or between the center level and the upper limit, Eq. (3) was used as follows (Cho \& Zoh, 2007; Karnik, Gaitonde, \& Davim, 2007):

$X_{i}=\frac{2 x_{i}-\left(x_{i, \max }+x_{i, \min }\right)}{\left(x_{i, \max }-x_{i, \min }\right)}$,

where $X_{i}$ is the coded manipulated variable; $x_{i}$ is the uncoded manipulated variable; $x_{i, \max }$ is the upper level of an uncoded manipulated variable; $x_{i, \min }$ is the lower level of an uncoded manipulated variable.

The response surface was related to the coded manipulated variables by a full second-order polynomial equation suggested by Box and Wilson in 1951 as follows (Bezerra et al., 2008; On the Experimental Attainment of Optimum Conditions on JSTOR, n.d.):

$Y=a_{0}+\sum_{i=1}^{k} a_{i} X_{i}+\sum_{i=1}^{k} \sum_{j=1}^{k} a_{i j} X_{i} X_{j}$

where $Y$ is the predicted response; $a_{0}, a_{i}, a_{i j}$ is the adjustable parameters.

Regarding the experimentally obtained data, the model adjustable parameters were calculated by the multiple linear regression analysis using the least-squares optimization method. The model validity was assessed using the analysis of variance (ANOVA) subroutine and by plotting internally studentized residuals versus run number and also by constructing a normal probability plot of internally studentized residuals.

\subsection{Desirability function optimization approach}

The desirability function optimization approach is a highly popular optimization technique used to simultaneously determine the optimum values of manipulated variables that can determine the optimum performance levels of one or more responses. During the optimization of a multivariate system, every single variable is converted into an individual desirability function with a value that varies from 0 to 1 , the lowest desirability value to the highest desirability value (Islam, Sakkas, \& Albanis, 2009; Mourabet et al., 2012). The individual desirability functions are then combined in an overall desirability function as follows (Bezerra et al., 2008; Paterakis, Korakianiti, Dallas, \& Rekkas, 2002):

$D=\left(\prod_{i=1}^{n} d_{i}\right)^{1 / n}$

where $D$ is the overall desirability; $d_{i}$ is the individual desirability; $n$ is the number of variables.

Depending on whether the target value of a particular variable is to be maximized, minimized or located between the lower limit and the upper limit, the individual desirability function is defined by Eqs. (6)-(8) (Bezerra et al., 2008; John, 2013):

$$
\begin{aligned}
& d_{i}= \begin{cases}0 & \text { if } z_{i} \leq L_{i}, \\
\left.\frac{z_{i}-L_{i}}{1}\right|^{p} & \text { if } L_{i} \leq z_{i} \leq T_{i},\end{cases} \\
& d_{i}= \begin{cases}1 & \text { if } z_{i} \geq T_{i}, \\
\left|\frac{z_{i}-U_{i}}{T_{i}-U_{i}}\right|^{q} & \text { if } T_{i} \leq z_{i} \leq U_{i}, \\
0 & \text { if } z_{i} \geq T_{i},\end{cases} \\
& d_{i}= \begin{cases}1 & \text { if } z_{i} \leq L_{i}, \\
\left|\frac{z_{i}-L_{i}}{T_{i}-L_{i}}\right|^{p} & \text { if } L_{i} \leq z_{i} \leq T_{i}, \\
\left|\frac{z_{i}-U_{i}}{T_{i}-U_{i}}\right|^{q} & \text { if } T_{i} \leq z_{i} \leq U_{i}, \\
0 & \text { if } z_{i} \geq U_{i},\end{cases}
\end{aligned}
$$

where $z_{i}$ is the variable; $L_{i}$ is the lower limit; $p, q$ is the importance weight; $U_{i}$ is the upper limit; $T_{i}$ is the target value.

\section{Results and discussion}

\subsection{Characterization analysis of silicon dioxide nanoparticles}

The surface morphology of silicon dioxide nanoparticles at two magnification levels $(100.0 \mathrm{kx}$ and $150.0 \mathrm{kx})$ is illustrated in 

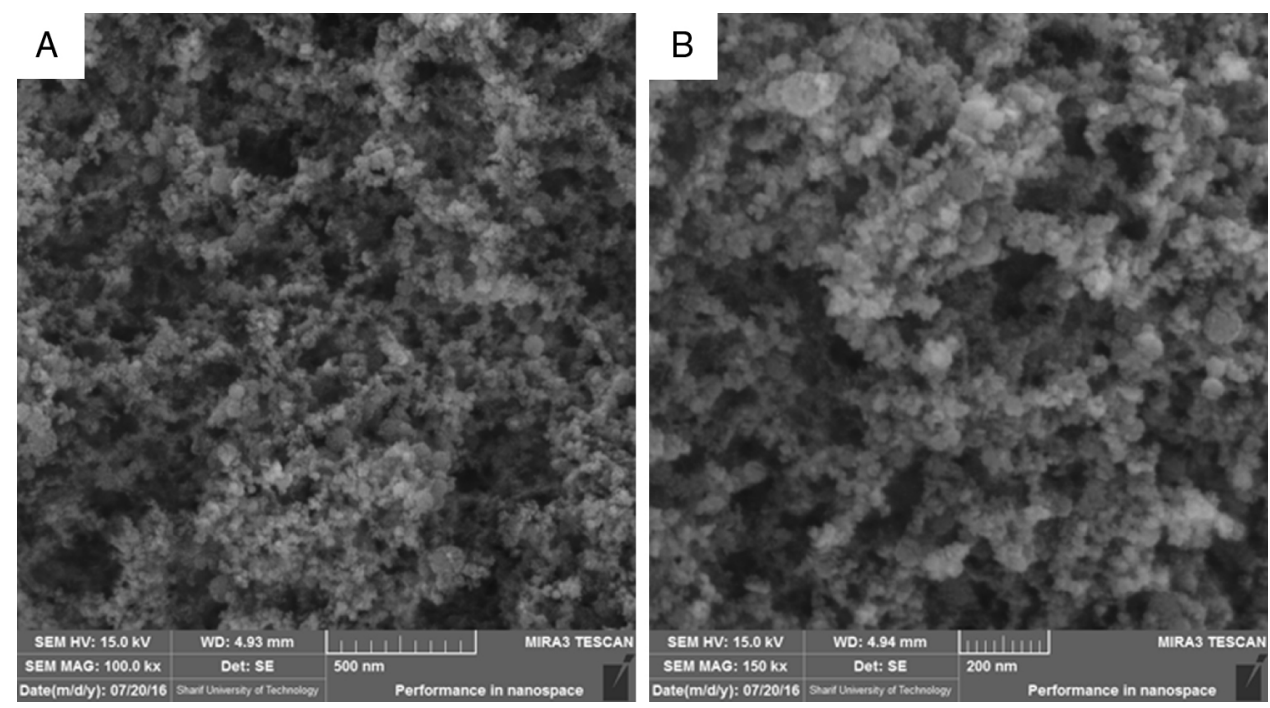

Fig. 1. FE-SEM images of silicon dioxide nanoparticles at: (A) $100.0 \mathrm{kx}$ and (B) $150.0 \mathrm{kx}$.

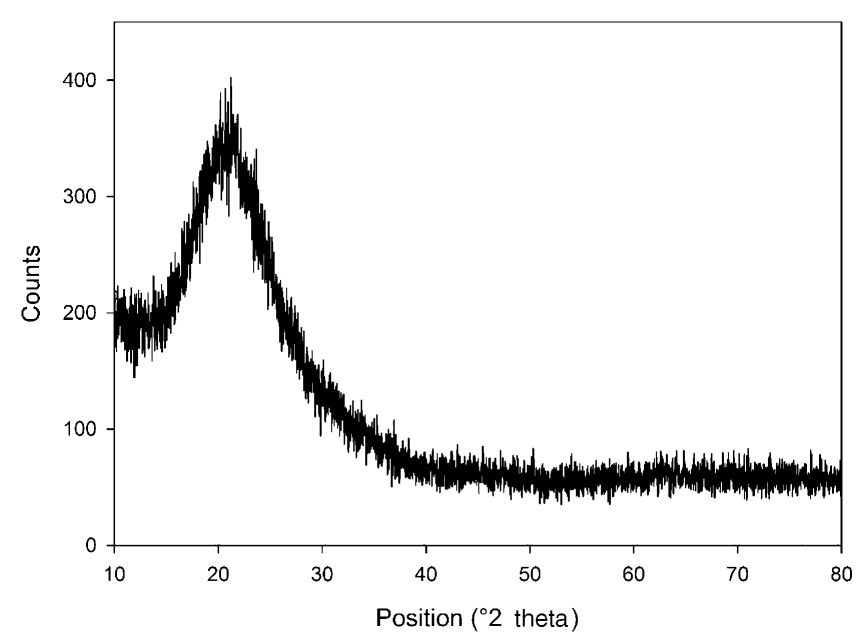

Fig. 2. XRD pattern of silicon dioxide nanoparticles.

Fig. 1. As this figure shows, silicon dioxide nanoparticles have a spherical and non-crystalline (or amorphous) morphology.

The XRD pattern of silicon dioxide nanoparticles in the range of $2 \theta=10-80^{\circ}$ is shown in Fig. 2. The low-intensity broad peak detected around $20^{\circ}$ indicates the presence of a non-crystalline silicon dioxide phase in the sample that is totally in agreement with the FE-SEM images. Similar observations have been reported in previous research works (Fang et al., 2008).

The size distribution of silicon dioxide nanoparticles in semi-logarithmic coordinates is plotted in Fig. 3. This figure clearly shows that most of the nanoparticles lie in the range of $10.0-15.0 \mathrm{~nm}$ in diameter. The results of the DLS analysis indicated that half of the silicon dioxide nanoparticles have an average diameter of about $12.80 \mathrm{~nm}$.

The quantitative chemical composition of impurities the sample of silicon dioxide nanoparticles determined by the ICP analysis and is listed in weight percentage in Table 2. A perusal of this table indicates that the purity of silicon dioxide in the sample is higher than $99.9 \mathrm{wt} . \%$.

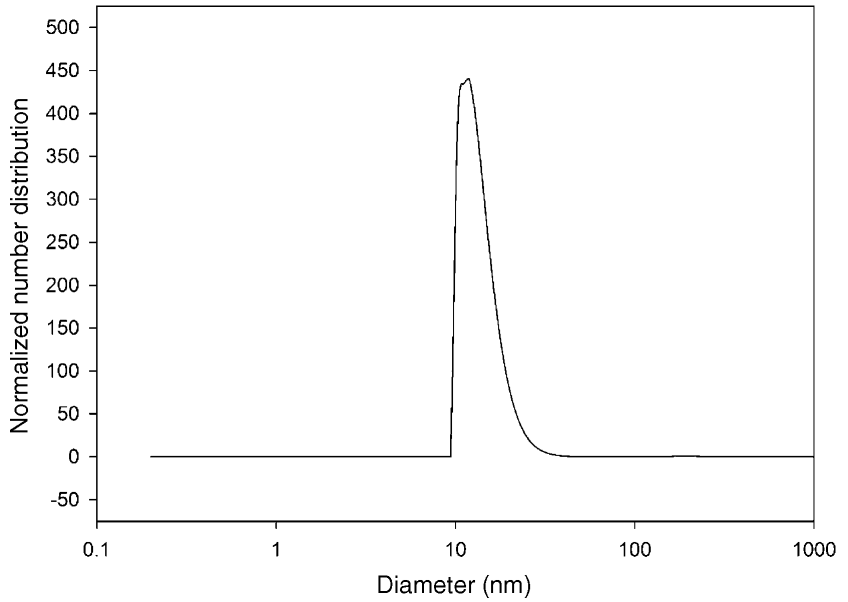

Fig. 3. Size distribution of silicon dioxide nanoparticles dispersed in deionized water.

Table 2

Quantitative chemical composition of impurities in the sample of silicon dioxide nanoparticles (by weight percent).

\begin{tabular}{ll}
\hline $\mathrm{Cu}$ & 0.0000000 \\
$\mathrm{Zn}$ & 0.0005884 \\
$\mathrm{Fe}$ & 0.0000000 \\
$\mathrm{Mg}$ & 0.0000042 \\
$\mathrm{Na}$ & 0.0000000 \\
$\mathrm{Al}$ & 0.0000000 \\
$\mathrm{As}$ & 0.0000000 \\
$\mathrm{Sb}$ & 0.0000031 \\
$\mathrm{~Pb}$ & 0.0000000 \\
$\mathrm{Hg}$ & 0.0000000 \\
\hline
\end{tabular}

Fig. 4A and $\mathrm{B}$ illustrates the $\mathrm{N}_{2}$ adsorption/desorption isotherm and the pore size distribution of the sample based on Barrett-Joyner-Halenda (BJH) model. The isotherm clearly shows that the hysteresis loop does not form even at high 

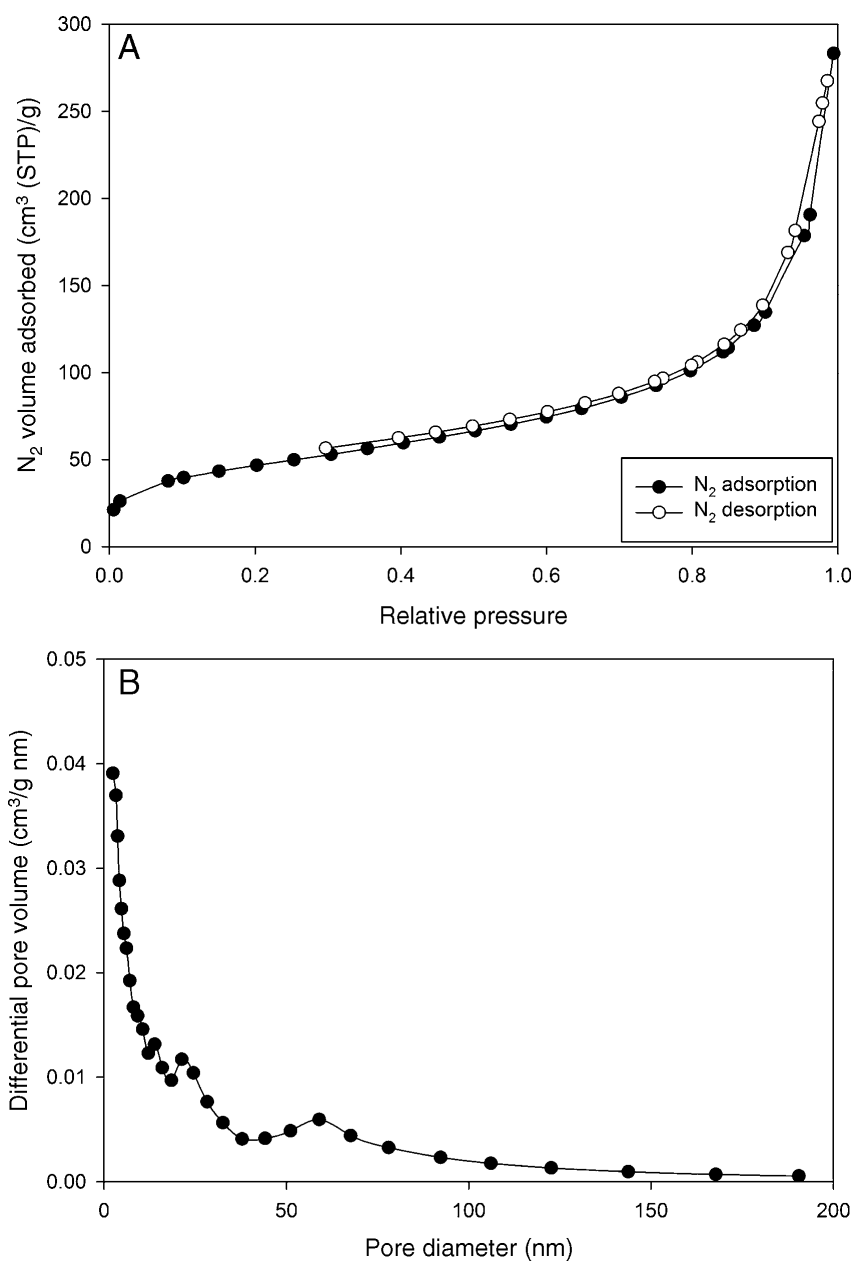

Fig. 4. (A) $\mathrm{N}_{2}$ adsorption/desorption isotherm and (B) BJH pore size distribution of silicon dioxide nanoparticles.

relative pressures, which suggests that the sample is not mesoporous (Naumov, 2009; Sing, 2001).

\subsection{Optimization of nanoparticles initial concentration}

The initial concentration of silicon dioxide nanoparticles was optimized by shaking $0.5 \mathrm{~g}$ of the CTAB-V samples with $50 \mathrm{~mL}$ of $100-1000 \mathrm{mg} / \mathrm{L}$ BA solutions at the initial $\mathrm{pH}$ value of $3.5 \mathrm{in}$ the presence of various concentrations of dispersed nanoparticles $(1,2,3,5,7.5$ and $10 \mathrm{mg} / \mathrm{L})$. Fig. 5 shows the equilibrium removal efficiency as a function of the initial concentration of silicon dioxide nanoparticles and BA. It can be observed from Fig. 5 that the equilibrium removal efficiency peaks at a certain initial concentration of nanoparticles and completely levels off afterwards. The initial concentration of nanoparticles was found to be optimum at $5 \mathrm{mg} / \mathrm{L}$ when the initial concentration of BA ranges between 100 and $400 \mathrm{mg} / \mathrm{L}$ and to be optimum at $7.5 \mathrm{mg} / \mathrm{L}$ when the initial concentration of $\mathrm{BA}$ in the range of $400-1000 \mathrm{mg} / \mathrm{L}$. Accordingly, the nanofluid of $7.5 \mathrm{mg} / \mathrm{L}$ of the initial concentration was used in order to equalize the conditions for the equilibrium adsorption isotherm experiments. Fig. 6 shows the equilibrium removal efficiency in the presence and absence of nanoparticles. As it displayed in Fig. 6,

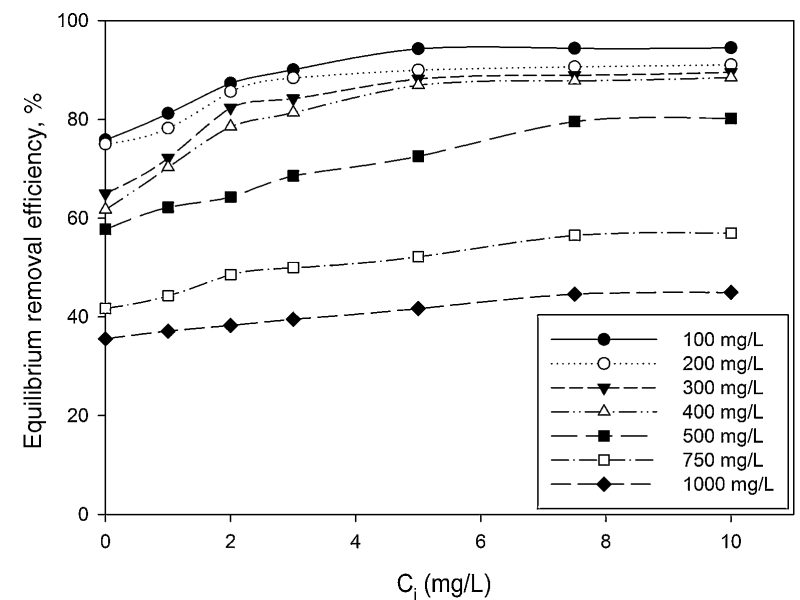

Fig. 5. The effect of initial concentration of silicon dioxide nanoparticles on the equilibrium removal efficiency at different initial concentrations of BA.

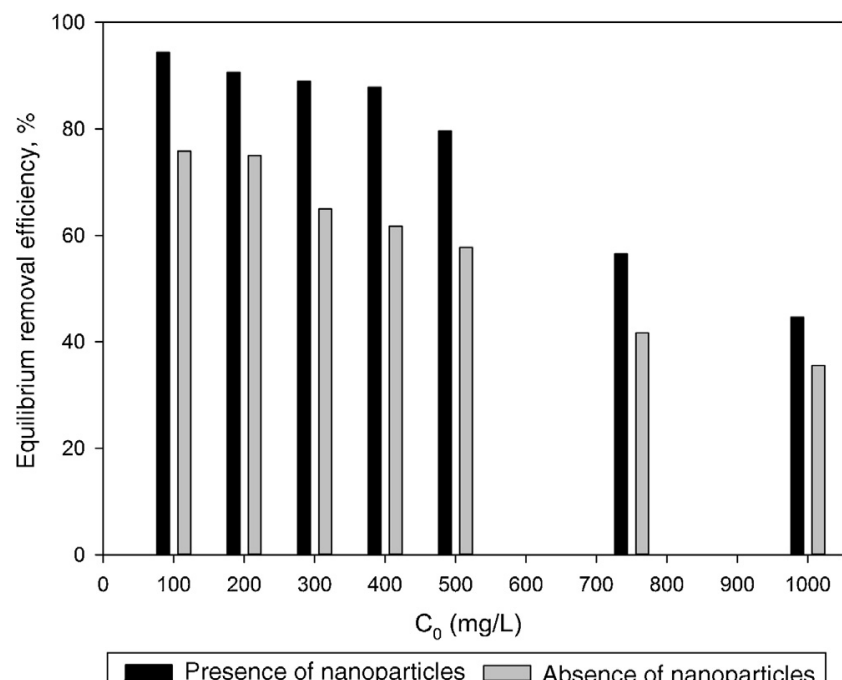

Fig. 6. The equilibrium removal efficiency of BA adsorption onto CTAB-V in the presence of $7.5 \mathrm{mg} / \mathrm{L}$ silicon dioxide nanoparticles and in their absence.

the equilibrium removal efficiency increases in the range of about $9-31.5 \%$ in the presence of $7.5 \mathrm{mg} / \mathrm{L}$ silicon dioxide nanoparticles in comparison with their absence when the initial concentration of BA varies from 100 to $1000 \mathrm{mg} / \mathrm{L}$. Since the colloidal stability of nanofluid has an extremely important effect on the performance of nanoparticles, the relative stability of $7.5 \mathrm{mg} / \mathrm{L}$ nanofluid was investigated as a function of the elapsed time using the UV/vis spectrophotometer method, as stated by Bahmanyar et al. (2011). For this purpose, the absorbency of nanofluid with an initial concentration of $7.5 \mathrm{mg} / \mathrm{L}$ was continually determined at a $\lambda_{\max }$ of $325 \mathrm{~nm}$ (corresponding to the maximum absorbance) over $12 \mathrm{~h}$ that is the required contact time for the equilibrium establishment. As the results are illustrated in Fig. 7, the relative concentration of suspended nanoparticles (the concentration at time $t$ divided by the initial concentration) reduces less than $7 \%$ within $12 \mathrm{~h}$, which is indicative of an adequate stability of nanofluid during the adsorption experiments. 


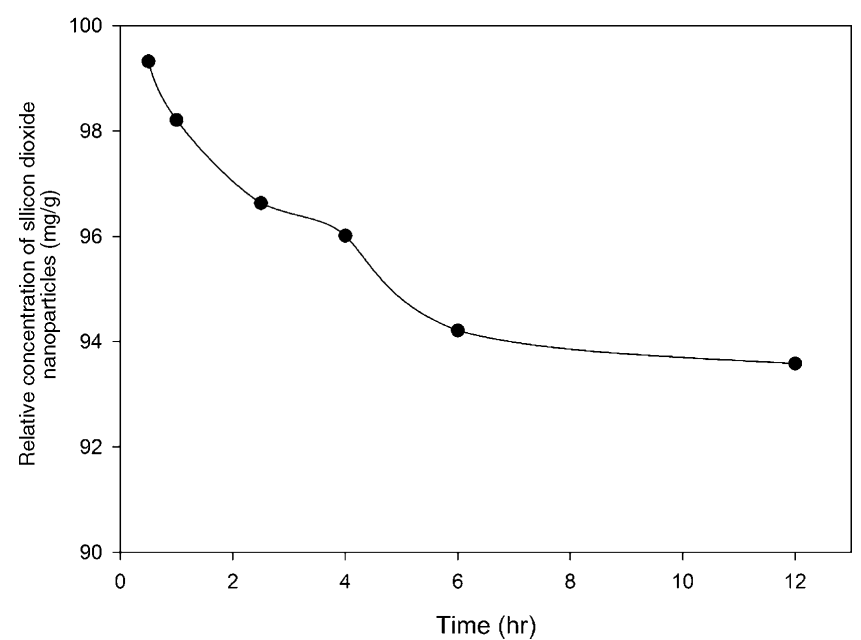

Fig. 7. The relative concentration of suspended silicon dioxide nanoparticles versus elapsed time.

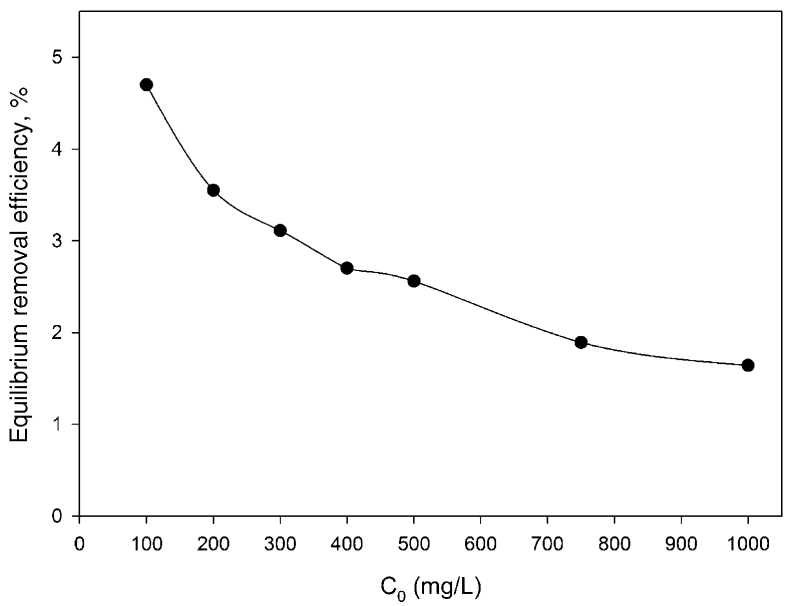

Fig. 8. The effect of $7.5 \mathrm{mg} / \mathrm{L}$ silicon dioxide nanoparticles on the equilibrium removal efficiency in the absence of CTAB-V.

The first probable explanation for the enhanced removal efficiency in the presence of silicon dioxide nanoparticles was the adsorption of BA by the mentioned nanoparticles. But this hypothesis was rejected because our additional experiments revealed that the dispersed hydrophilic silicon dioxide nanoparticles at the aforementioned concentrations do not have any remarkable affinity toward BA without introducing CTAB-V into the adsorption system. As shown in Fig. 8, the equilibrium removal efficiency of $100-1000 \mathrm{mg} \mathrm{BA} / \mathrm{L}$ in a $7.5 \mathrm{mg} / \mathrm{L}$ silicon dioxide nanofluid in the absence of $\mathrm{CTAB}-\mathrm{V}$ was found to be up to a maximum of approximately $4.7 \%$. In contrast, Jasper et al. (2010) have found from their adsorbent-free experiments that both titanium dioxide and iron(III) oxide nanoparticles alone act as adsorption sites for up to $60 \%$ of trichloroethylene. Hence, it was concluded that the presence of nanoparticles certainly has a positive side effect on the adsorptive behavior of BA. It can be proposed that the increase in BA removal efficiency may correspond to the increase in BA mass diffusion rate in the liquid phase arising from the Brownian motion of nanoparticles that creates micro/nanoscale convection through the interstices
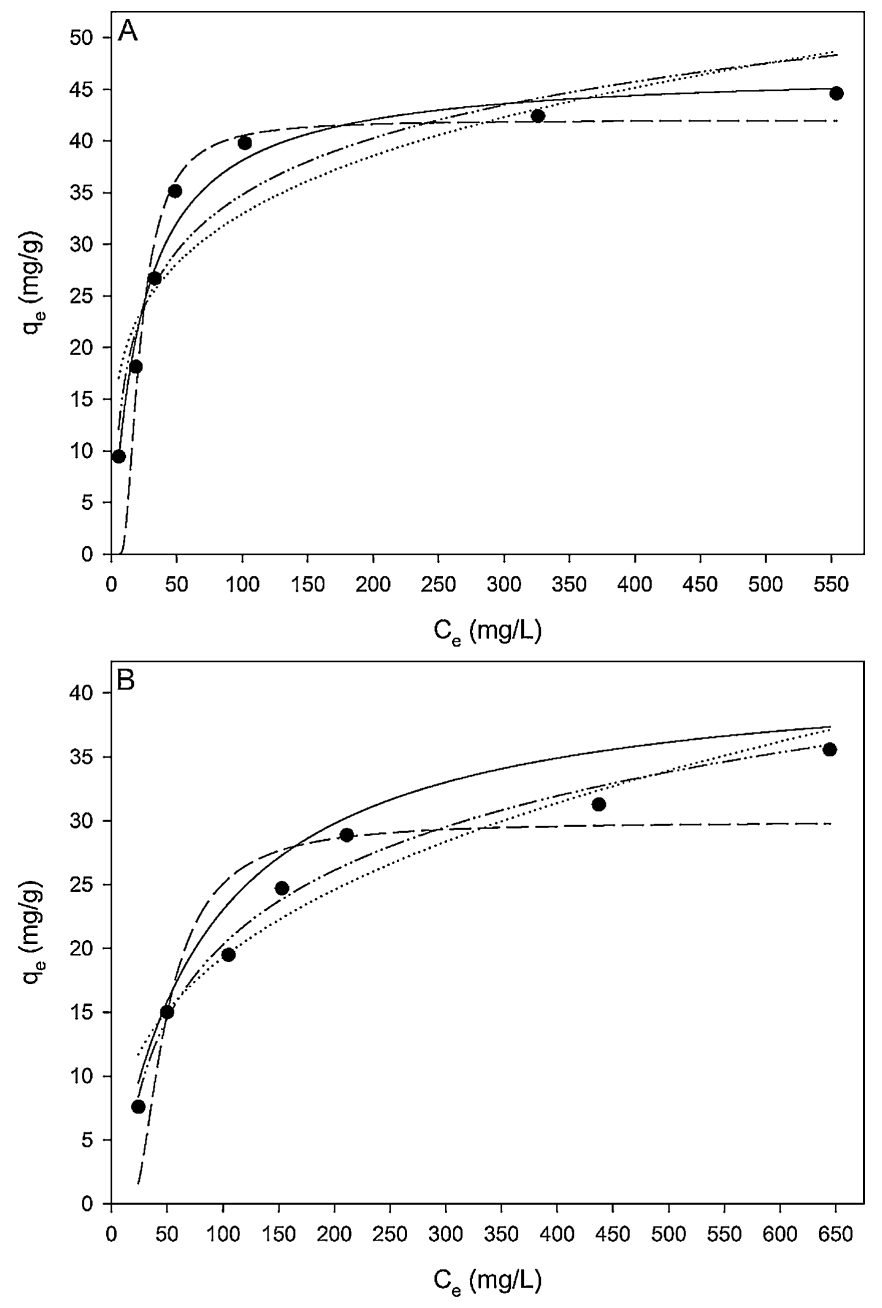

- Experiment Langmuir ….............. Freundlich

- - - Dubinin-Radushkevich -..-.._.. Temkin

Fig. 9. The equilibrium isotherm of $\mathrm{BA}$ adsorption onto $\mathrm{CTAB}-\mathrm{V}$ at $30^{\circ} \mathrm{C}$ : (A) in the presence of $7.5 \mathrm{mg} / \mathrm{L}$ silicon dioxide nanoparticles and (B) in the absence of nanoparticles.

of adsorbent particles (Ashrafmansouri \& Nasr Esfahany, 2014; Krishnamurthy et al., 2006).

\subsection{Equilibrium adsorption isotherm}

The Langmuir, Freundlich, Dubinin-Radushkevich and Temkin models were used to analyze the equilibrium data. The mathematical expression of these models is given in Eqs. (5)-(8) (Foo \& Hameed, 2010; Ho, Porter, \& McKay, 2002):

$q_{e}=\frac{q_{L} K_{L} C_{e}}{1+K_{L} C_{e}}$

$q_{e}=K_{F} C_{e}^{1 / n_{F}}$,

$q_{e}=q_{D-R} \exp \left(-K_{D-R}\left[R T \ln \left(1+\frac{1}{C_{e}}\right)\right]^{2}\right)$,

$q_{e}=\frac{R T}{b_{T}} \ln \left(A_{T} C_{e}\right)$, 

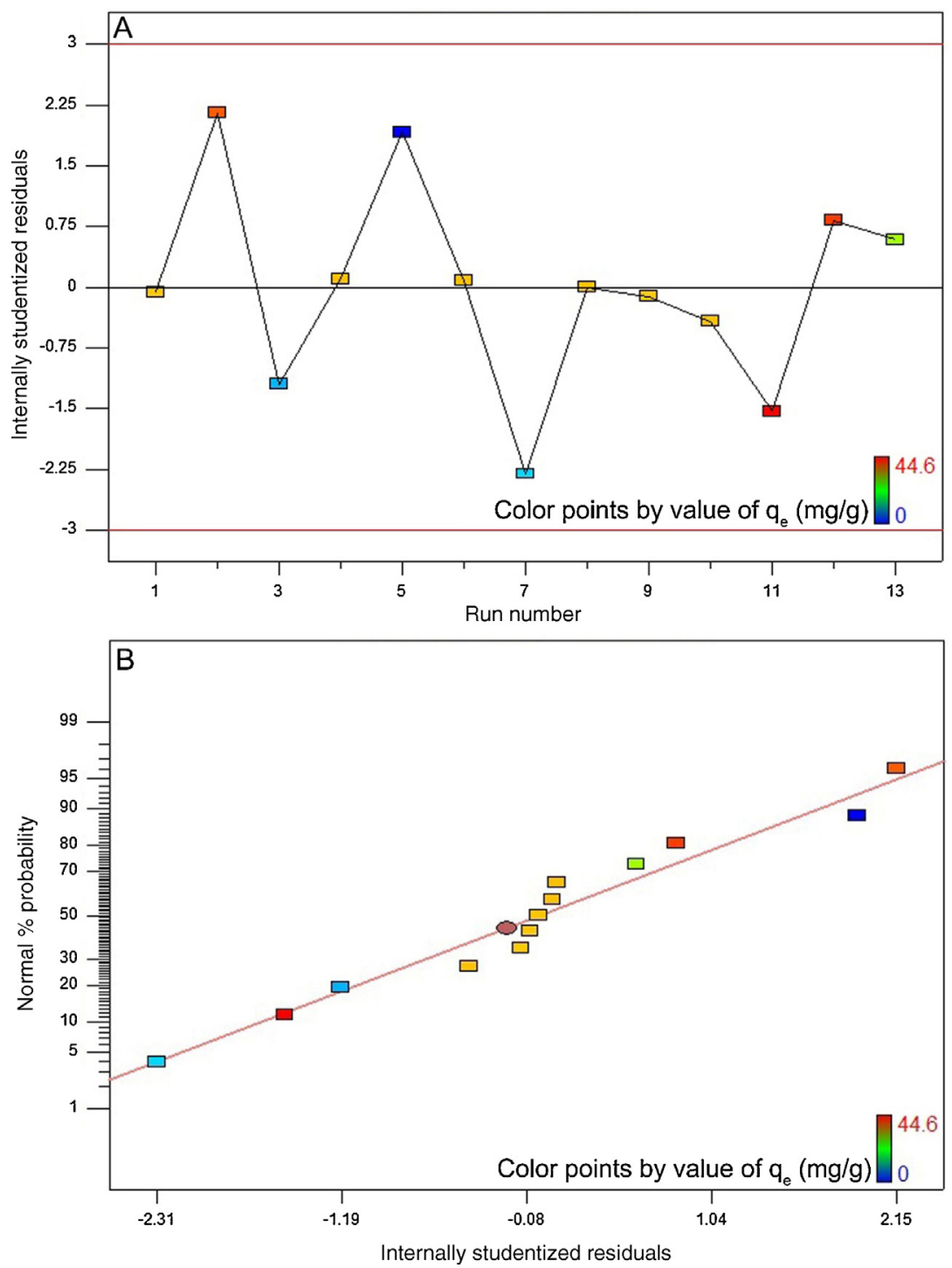

Fig. 10. (A) The internally studentized residuals versus run number and (B) the normally probability plot of the internally studentized residuals.

where $q_{L}$ is the Langmuir adsorption capacity; $K_{L}$ is the Langmuir isotherm constant; $K_{F}$ is the Freundlich isotherm constant; $n_{F}$ is the Freundlich adsorption intensity constant; $q_{D-R}$ is the Dubinin-Radushkevich adsorption capacity; $K_{D-R}$ is the Dubinin-Radushkevich isotherm constant; $R$ is the Universal gas constant; $T$ is the temperature; $b_{T}$ is the Temkin isotherm constant; $A_{T}$ is the Temkin isotherm equilibrium constant.

The adjustable parameters together with the coefficient of determination for each isotherm model was calculated using the MATLAB nonlinear least-squares optimization routine. The values of $q_{e}$ from the experiments and from the models were also compared based on the average absolute relative deviation (AARD) defined as follows (Foo \& Hameed, 2010):

$\operatorname{AARD}(\%)=\frac{100}{N} \sum_{i=1}^{N}\left|\frac{q_{e, \exp }-q_{e, \mathrm{cal}}}{q_{e, \exp }}\right|$, where $N$ is the number of data points; $q_{e, \text { exp }}$ is the experimental adsorption capacity at equilibrium; $q_{e, \text { cal }}$ is the calculated adsorption capacity at equilibrium.

Fig. 9A and B shows the experimental equilibrium data and the predicted equilibrium isotherms for $\mathrm{BA}$ adsorption onto CTAB-V in the presence and absence of nanoparticles. According to Alberti, Amendola, Pesavento, and Biesuz (2012), it is apparent that the shape of experimental isotherm alters from the Langmuir type (without strict plateau) in the absence of silicon dioxide nanoparticles to the high affinity type in the case of nanoparticles presence. This in turn manifests that the adsorption of BA onto CTAB-V takes place more favorably in the presence of nanoparticles (Kyzas \& Matis, 2015). Table 3 tabulates the fitting results together with the AARD values for each isotherm model. As can be seen, the equilibrium data are better fitted to the Langmuir and Temkin models in the absence of nanoparticles whereas in the presence of nanoparticles, they are satisfactorily fitted by just the Langmuir model. 

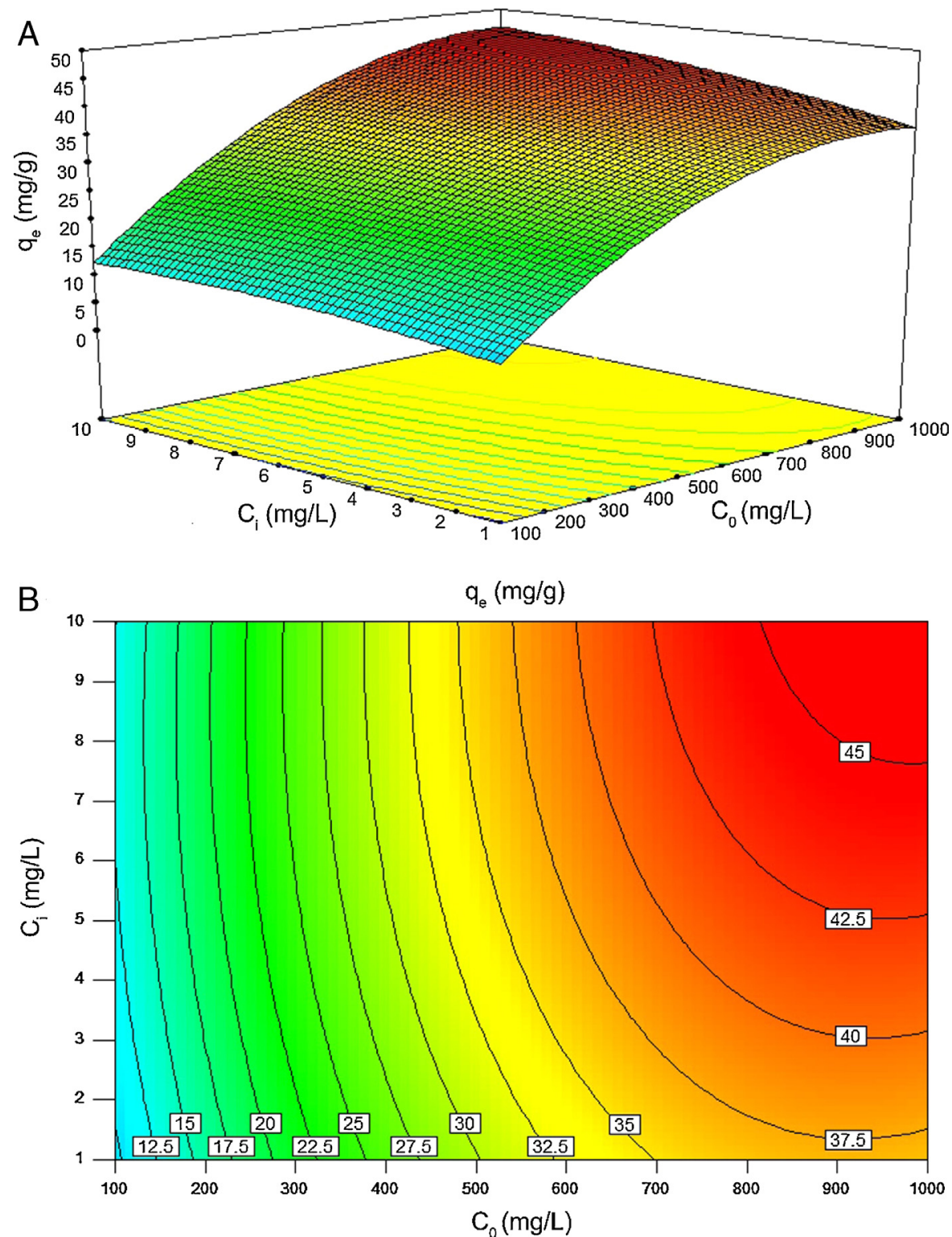

Fig. 11. The effect of BA and silicon dioxide nanoparticles on the equilibrium adsorption capacity of CTAB-V: (A) three dimensional response surface plot and (B) two dimensional contour plot.

\subsection{RSM-based model}

By fitting the results from the designed experiments to Eq. (4), the model predicting the equilibrium capacity of CTAB$\mathrm{V}$ in terms of coded manipulated variables was derived as follows:

$$
\begin{aligned}
q_{e} & =36.01+15.32 C_{0}+3.21 C_{i}+1.74 C_{0} C_{i}-8.38 C_{0}^{2} \\
& -1.36 C_{i}^{2} .
\end{aligned}
$$

The high coefficient of determination (0.988) and Fisher value (115.1) verified the model adequacy. Additionally, the probability value was about 0.000 . By definition, if the probability value is less than 0.05 , the model is statistically considered significant and the Fisher value is high enough. The latter signifies that the most of variations in the response can be predicted by the model (Jain et al., 2011; Murugesan et al., 2014). Fig. 10A depicts the internally studentized residuals against the run number. It is evident from this figure that the differences between the actual and the model-predicted responses fall within the acceptable range, i.e. from -3 to +3 in the context of internally studentized residual (Dopar, Kusic, \& Koprivanac, 2011; Jadhav, Surwase, Phugare, \& Jadhav, 2012). Therefore, it is possible to conclude that there were no outliers among the experimental data set. Fig. 10B depicts the normal probability plot of internally studentized residuals. It is clear that the points in this figure are appropriately located near to the diagonal straight line. This satisfies the normality assumption. In other words, it corroborates the normal distribution of errors around the mean value and 
Table 3

Isotherm model parameters, coefficients of determination and AARD values for BA adsorption onto CTAB- $\mathrm{V}$ in the presence of $7.5 \mathrm{mg} / \mathrm{L}$ silicon dioxide nanoparticles and in their absence.

\begin{tabular}{lll}
\hline Isotherm model & \multicolumn{2}{l}{ Isotherm parameters } \\
\cline { 2 - 3 } & $\begin{array}{l}\text { Presence of } \\
\text { nanoparticles }\end{array}$ & $\begin{array}{l}\text { Absence of } \\
\text { nanoparticles }\end{array}$ \\
\hline Langmuir & $q_{L}=47.32$ & $q_{L}=42.18$ \\
& $K_{L}=0.036$ & $K_{L}=0.012$ \\
& $R^{2}=0.952$ & $R^{2}=0.991$ \\
& AARD & AARD \\
& $(\%)=7.021$ & $(\%)=6.051$ \\
& $K_{F}=10.90$ & $K_{F}=3.818$ \\
Freundlich & $n=4.237$ & $n=2.844$ \\
& $R^{2}=0.788$ & $R^{2}=0.920$ \\
& AARD & AARD \\
& $(\%)=22.03$ & $(\%)=12.34$ \\
Dubinin-Radushkevich & $q_{D-R}=43.02$ & $q_{D-R}=29.9$ \\
& $K_{D-R}=93.68$ & $K_{D-R}=280.6$ \\
& $R^{2}=0.891$ & $R^{2}=0.791$ \\
& AARD & AARD \\
& $(\%)=16.14$ & $(\%)=20.72$ \\
Temkin & $A_{T}=0.754$ & $A_{T}=0.112$ \\
& $b_{T}=0.318$ & $b_{T}=0.303$ \\
& $R^{2}=0.885$ & $R^{2}=0.984$ \\
& AARD & AARD \\
& $(\%)=11.72$ & $(\%)=5.232$ \\
& &
\end{tabular}

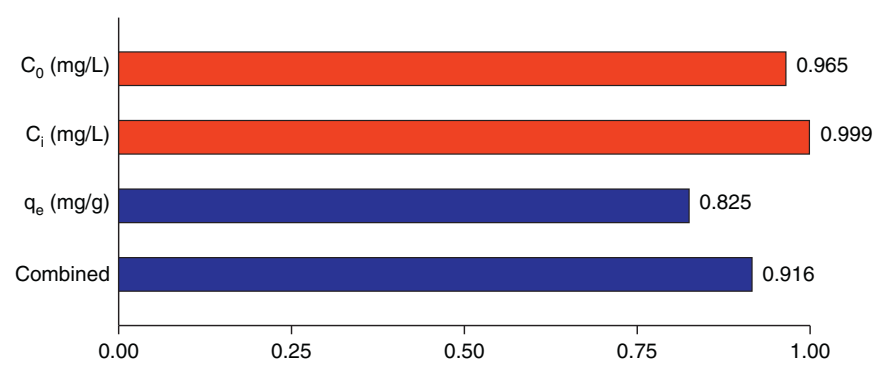

Fig. 12. The individual desirability value of each variable and their combination.

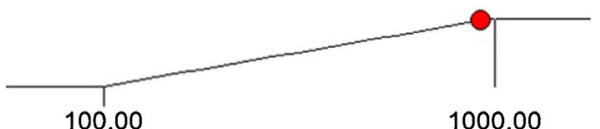

1000.00

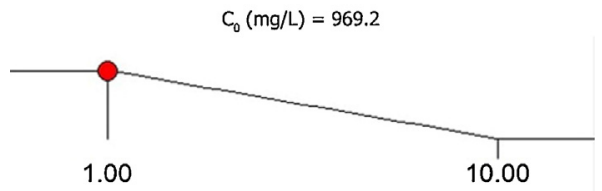

$C_{1}(m g / L)=1$

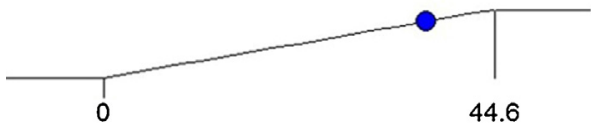

$\mathrm{q}_{\mathrm{e}}(\mathrm{mg} / \mathrm{g})=36.83$

Fig. 13. Desirability value ramps for optimization of variables.

their independency from each other (Dopar et al., 2011; Jadhav et al., 2012). The mean and variance values of the internally studentized residuals in this study were found to be 0.044 and 1.342, respectively. Statistically, as the mean value of a group of data tends to zero and their variance value tends to unity, the distribution of those data is taken to be standard normal (Montgomery \& Runger, 2010). Fig. 10A and B further confirms the validity of the suggested model.

Fig. 11A and B illustrates the individual and cumulative impacts of the initial concentrations of BA and nanoparticles on the equilibrium adsorption capacity in the choice of test range in three-dimensional response surface plot and two-dimensional contour plot, respectively. The plots represent that the adsorption capacity increases by increasing the initial concentrations of both BA and nanoparticles. Fig. 11A shows that the initial concentration of BA has a more profound effect on the response amplitude than the initial concentration of nanoparticles. The

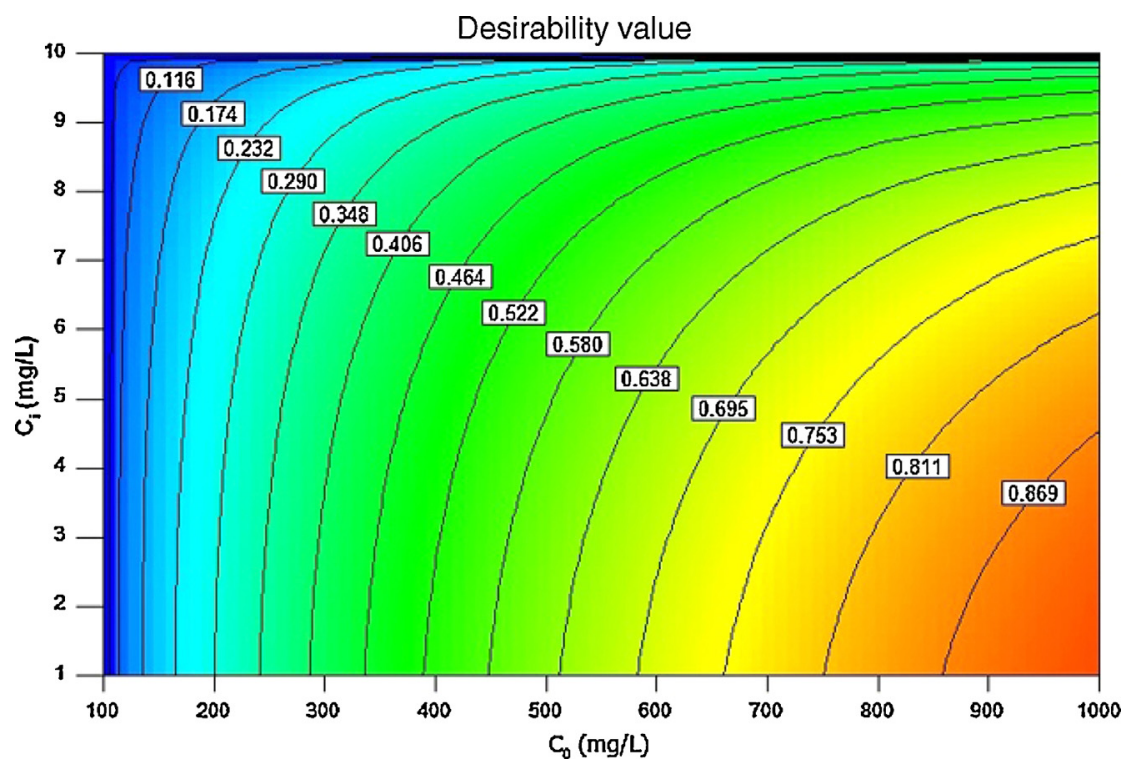

Fig. 14. Effect of BA and silicon dioxide nanoparticles initial concentration on combined desirability value. 
curvature of contour lines denotes to what extent the independent variables have communal interactions. If the shape of the contour lines is more elliptical rather than circular, the interactive effect of independent variables on the predicted response is more significant. As it illustrated in Fig. 11B, the contour lines are of elliptical type in this study, which means that the interactions between $C_{0}$ and $C_{i}$ are likely to be of great significance to the equilibrium adsorption capacity (Jadhav et al., 2012; Zhong \& Wang, 2010).

\subsection{Desirability function optimization}

A maximum level of BA initial concentration, minimum level of silicon dioxide nanoparticles initial concentration and maximum level of CTAB-V adsorption capacity were set for the maximum desirability. By seeking from 30 points per optimizations that is the software default and considering the importance of each variable the highest value that can vary from 1 to 5 , the best local conditions were found to be the initial concentration of BA at $969.2 \mathrm{mg} / \mathrm{L}$, the initial concentration of silicon dioxide nanoparticles at $1 \mathrm{mg} / \mathrm{L}$ and the adsorbent capacity at about $36.83 \mathrm{mg} / \mathrm{g}$. Fig. 12 shows the optimum values for all variables suggested by the software. The effect of BA and silicon dioxide nanoparticles initial concentration on the combined desirability values is h shown in Fig. 13. Fig. 14 also shows the values of individual desirability values as well as the combined desirability value that was found to be 0.916 , which indicates the reliability of the optimizations process.

\section{Conclusions}

To sum up, the batch adsorption of BA from aqueous solution onto CTAB-V at equilibrium was compared in the presence and absence of hydrophilic silicon dioxide nanoparticles in this research. An RSM-based model was also developed for investigating the equilibrium adsorption capacity by varying the initial concentrations of BA and nanoparticles. The main conclusions can be summarized as below:

(I) A 5 and $7.5 \mathrm{mg} / \mathrm{L}$ initial concentration of nanoparticles optimizes the equilibrium efficiency of BA adsorption onto CTAB-V when the initial concentration of BA is 100-400 and 400-1000 mg/L, respectively.

(II) The equilibrium removal efficiency of BA in the presence of $7.5 \mathrm{mg} / \mathrm{L}$ nanoparticles increases by between about $9.0 \%$ and $31.5 \%$ when the initial concentration of $\mathrm{BA}$ varies from 100 to $1000 \mathrm{mg} / \mathrm{L}$.

(III) The equilibrium adsorption isotherm changes from the Langmuir type (without strict plateau) in the absence of nanoparticles to the high affinity type in the presence of nanoparticles, which implies the more favorable adsorptive behavior of CTAB-V when the nanoparticles are present.

(IV) In the presence of nanoparticles, the equilibrium data are better fitted to the Langmuir model compared to the Freundlich, Dubinin-Radushkevich and Temkin models. In the absence of nanoparticles, the equilibrium data are better fitted to the Langmuir and Temkin models compared to the two other models.

(V) The RSM-based model reliability was confirmed by the high coefficient of determination and Fisher value as well as the probability value of less than 0.05 . The range of internally studentized residuals was acceptable (between -3 and +3 ) and they were normally distributed owing to their mean and variance values very close to zero and unity, respectively.

(VI) The interactive effect of the initial concentrations of BA and nanoparticles on the equilibrium adsorption capacity was found to be noticeable resulting from the elliptical form of contours. Individually, it was observed that the initial concentration of BA has a larger effect on the response than the initial concentration of nanoparticles.

(VII) The desirability function optimization approach showed that the best local conditions are to be the initial concentration of BA at $969.2 \mathrm{mg} / \mathrm{L}$, the initial concentration of silicon dioxide nanoparticles at $1 \mathrm{mg} / \mathrm{L}$ and the adsorbent capacity at about $36.83 \mathrm{mg} / \mathrm{g}$.

\section{Conflict of interest}

The authors have no conflicts of interest to declare.

\section{Acknowledgements}

The authors are sincerely grateful to the editors and anonymous reviewers of the Journal of Applied Research and Technology for their insightful comments and suggestions on an earlier draft of this article. The authors would also like to wholeheartedly acknowledge Prof. Parissa Khadiv-Parsi, Mr. Amir Yadegari, Mr. Amir Rouhi, Ms. Maryam Nedaei and Dr. Mohammad Foroughi-dahr for their unwavering scientific support and encouragement.

\section{References}

Alberti, G., Amendola, V., Pesavento, M., \& Biesuz, R. (2012). Beyond the synthesis of novel solid phases: Review on modelling of sorption phenomena. Coordination Chemistry Reviews, 256(1-2), 28-45. http://dx.doi.org/10.1016/j.ccr.2011.08.022

Anirudhan, T. S., \& Ramachandran, M. (2006). Adsorptive removal of tannin from aqueous solutions by cationic surfactant-modified bentonite clay. Journal of Colloid and Interface Science, 299(1), 116-124. http://dx.doi.org/10.1016/j.jcis.2006.01.056

Arulkumar, M., Sathishkumar, P., \& Palvannan, T. (2011). Optimization of Orange $\mathrm{G}$ dye adsorption by activated carbon of Thespesia populnea pods using response surface methodology. Journal of Hazardous Materials, 186(1), 827-834. http://dx.doi.org/10.1016/j.jhazmat.2010.11.067

Ashrafmansouri, S.-S., \& Nasr Esfahany, M. (2014). Mass transfer in nanofluids: A review. International Journal of Thermal Sciences, 82, 84-99. http://dx.doi.org/10.1016/j.ijthermalsci.2014.03.017

Bahmanyar, A., Khoobi, N., Mozdianfard, M. R., \& Bahmanyar, H. (2011). The influence of nanoparticles on hydrodynamic characteristics and mass transfer performance in a pulsed liquid-liquid extraction column. Chemical Engineering and Processing: Process Intensification, 50(11-12), 1198-1206. http://dx.doi.org/10.1016/j.cep.2011.08.008

Banaei, A., Vojoudi, H., Karimi, S., Bahar, S., \& Pourbasheer, E. (2015). Synthesis and characterization of new modified silica coated magnetite 
nanoparticles with bisaldehyde as selective adsorbents of $\mathrm{Ag}(\mathrm{I})$ from aqueous samples. RSC Advances, 5. http://dx.doi.org/10.1039/c5ra11765h

Bezerra, M. A., Santelli, R. E., Oliveira, E. P., Villar, L. S., \& Escaleira, L. A. (2008). Response surface methodology (RSM) as a tool for optimization in analytical chemistry. Talanta, 76(5), 965-977. http://dx.doi.org/10.1016/j.talanta.2008.05.019

Borisover, M., \& Davis, J. A. (2015). Natural and engineered clay barriers. Developments in clay science (Vol. 6) Elsevier. http://dx.doi.org/10.1016/B978-0-08-100027-4.00002-4

Cho, I.-H., \& Zoh, K.-D. (2007). Photocatalytic degradation of azo dye (Reactive Red 120) in $\mathrm{TiO}_{2} / \mathrm{UV}$ system: Optimization and modeling using a response surface methodology (RSM) based on the central composite design. Dyes and Pigments, 75(3), 533-543. http://dx.doi.org/10.1016/j.dyepig.2006.06.041

Choolaei, M., Rashidi, A. M., Ardjmand, M., Yadegari, A., \& Soltanian, H. (2012). The effect of nanosilica on the physical properties of oil well cement. Materials Science and Engineering A, 538, 288-294. http://dx.doi.org/10.1016/j.msea.2012.01.045

De Araújo Medeiros, M., Sansiviero, M. T. C., Araújo, M. H., \& Lago, R. M. (2009). Modification of vermiculite by polymerization and carbonization of glycerol to produce highly efficient materials for oil removal. Applied Clay Science, 45(4), 213-219. http://dx.doi.org/10.1016/j.clay.2009.06.008

Dopar, M., Kusic, H., \& Koprivanac, N. (2011). Treatment of simulated industrial wastewater by photo-Fenton process. Part I: The optimization of process parameters using design of experiments (DOE). Chemical Engineering Journal, 173(2), 267-279. http://dx.doi.org/10.1016/j.cej.2010.09.070

Fang, J., Shan, X., Wen, B., Lin, J., Lu, X., Liu, X., et al. (2008). Sorption and desorption of phenanthrene onto iron, copper, and silicon dioxide nanoparticles. Langmuir: The ACS Journal of Surfaces and Colloids, 24(6), 10929-10935. http://dx.doi.org/10.1021/la801459s

Filipović-Petrović, L. M., Kostić-Gvozdenović, L., \& Erić-Antonić, S. Ć. (2002). The effects of fine grinding on the physicochemical properties and thermal behavior of bentonite clay. Journal of the Serbian Chemical Society, 67(11), 753-760. Retrieved from http://www. doiserbia.nb.rs/Article.aspx?ID=0352-51390211753F\&AspxAutoDetect CookieSupport=1\#.VfW1aJcqFUE

Foo, K. Y., \& Hameed, B. H. (2010). Insights into the modeling of adsorption isotherm systems. Chemical Engineering Journal, 156(1), 2-10. http://dx.doi.org/10.1016/j.cej.2009.09.013

Gandhi, V. G., Mishra, M. K., Rao, M. S., Kumar, A. A., Joshi, P., \& Shah, D. O. (2011). Comparative study on nano-crystalline titanium dioxide catalyzed photocatalytic degradation of aromatic carboxylic acids in aqueous medium. Journal of Industrial and Engineering Chemistry, 17(2), 331-339. http://dx.doi.org/10.1016/j.jiec.2011.02.035

Garg, K. K., \& Prasad, B. (2015). Electrochemical treatment of benzoic acid (BA) from aqueous solution and optimization of parameters by response surface methodology (RSM). Journal of the Taiwan Institute of Chemical Engineers, 56, 122-130. http://dx.doi.org/10.1016/j.jtice.2015.04.005

Giannakas, A. E., Antonopoulou, M., Deligiannakis, Y., \& Konstantinou, I. (2013). Preparation, characterization of N-I co-doped $\mathrm{TiO}_{2}$ and catalytic performance toward simultaneous $\mathrm{Cr}(\mathrm{VI})$ reduction and benzoic acid oxidation. Applied Catalysis B: Environmental, 140-141, 636-645. http://dx.doi.org/10.1016/j.apcatb.2013.04.052

Gupta, S., \& Bhattacharyya, K. G. (2011). Kinetics of adsorption of metal ions on inorganic materials: A review. Advances in Colloid and Interface Science, 162(1-2), 39-58. http://dx.doi.org/10.1016/j.cis.2010.12.004

Ho, Y. S., Porter, J. F., \& McKay, G. (2002). Equilibrium isotherm studies for the sorption of divalent metal ions onto peat: Copper, nickel and lead single component systems. Water, Air, and Soil Pollution, 141(1-4), 1-33. http://dx.doi.org/10.1023/A:1021304828010

Hongo, T., Yoshino, S., Yamazaki, A., Yamasaki, A., \& Satokawa, S. (2012). Mechanochemical treatment of vermiculite in vibration milling and its effect on lead(II) adsorption ability. Applied Clay Science, 70, 74-78. http://dx.doi.org/10.1016/j.clay.2012.09.016

Huang, J., Wang, G., \& Huang, K. (2011). Enhanced adsorption of salicylic acid onto a $\beta$-naphthol-modified hyper-cross-linked poly(styreneco-divinylbenzene) resin from aqueous solution. Chemical Engineering Journal, 168(2), 715-721. http://dx.doi.org/10.1016/j.cej.2011.01.065
Islam, M. A., Sakkas, V., \& Albanis, T. A. (2009). Application of statistical design of experiment with desirability function for the removal of organophosphorus pesticide from aqueous solution by low-cost material. Journal of Hazardous Materials, 170(1), 230-238. http://dx.doi.org/10.1016/j.jhazmat.2009.04.106

Jadhav, S. B., Surwase, S. N., Phugare, S. S., \& Jadhav, J. P. (2012). Response surface methodology mediated optimization of Remazol Orange decolorization in plain distilled water by Pseudomonas aeruginosa $\mathrm{BCH}$ International Journal of Environmental Science and Technology, 10(1), 181-190. http://dx.doi.org/10.1007/s13762-012-0088-9

Jain, M., Garg, V. K., \& Kadirvelu, K. (2011). Investigation of $\mathrm{Cr}(\mathrm{VI})$ adsorption onto chemically treated Helianthus annuus: Optimization using response surface methodology. Bioresource Technology, 102(2), 600-605. http://dx.doi.org/10.1016/j.biortech.2010.08.001

Jasper, A., Salih, H. H., Sorial, G. A., Sinha, R., Krishnan, R., \& Patterson, C. L. (2010). Impact of nanoparticles and natural organic matter on the removal of organic pollutants by activated carbon adsorption. Environmental Engineering Science, 27(1), 85-93. http://dx.doi.org/10.1089/ees.2009. 0234

Jiménez De Haro, M., Martıńez Blanes, J., Poyato, J., Pérez-Maqueda, L., Lerf, A., \& Pérez-Rodríguez, J. (2004). Effects of mechanical treatment and exchanged cation on the microporosity of vermiculite. Journal of Physics and Chemistry of Solids, 65(2-3), 435-439. http://dx.doi.org/10.1016/j.jpcs.2003.08.033

John, B. (2013). Application of desirability function for optimizing the performance characteristics of carbonitrided bushes. International Journal of Industrial Engineering Computations, 4(3), 305-314. http://dx.doi.org/10.5267/j.ijiec.2013.04.003

Karnik, S. R., Gaitonde, V. N., \& Davim, J. P. (2007). A comparative study of the ANN and RSM modeling approaches for predicting burr size in drilling. The International Journal of Advanced Manufacturing Technology, 38(9-10), 868-883. http://dx.doi.org/10.1007/s00170-007-1140-7

Khoobi, N., Bahmanyar, A., Molavi, H., Bastani, D., Mozdianfard, M. R., \& Bahmanyar, H. (2013). Study of droplet behaviour along a pulsed liquid-liquid extraction column in the presence of nanoparticles. The Canadian Journal of Chemical Engineering, 91(3), 506-515. http://dx.doi.org/10.1002/cjce.21679

Knepper, T., Sacher, F., Lange, F., Brauch, H., Karrenbrock, F., Roerden, O., et al. (1999). Detection of polar organic substances relevant for drinking water. Waste Management, 19(2), 77-99. http://dx.doi.org/10.1016/S0956-053X(99)00003-3

Krishnamurthy, S., Bhattacharya, P., Phelan, P. E., \& Prasher, R. S. (2006). Enhanced mass transport in nanofluids. Nano Letters, 6(3), 419-423. http://dx.doi.org/10.1021/n10522532

Kyzas, G. Z., \& Matis, K. A. (2015). Nanoadsorbents for pollutants removal: A review. Journal of Molecular Liquids, 203, 159-168. http://dx.doi.org/10.1016/j.molliq.2015.01.004

Montgomery, D. C., \& Runger, G. C. (2010). Applied statistics and probability for engineers. John Wiley \& Sons. Retrieved from https://books.google.com/books?id=_f4KrEcNAfEC\&pgis=1

Mourabet, M., El Rhilassi, A., El Boujaady, H., Bennani-Ziatni, M., El Hamri, R., \& Taitai, A. (2012). Removal of fluoride from aqueous solution by adsorption on Apatitic tricalcium phosphate using Box-Behnken design and desirability function. Applied Surface Science, 258(10), 4402-4410. http://dx.doi.org/10.1016/j.apsusc.2011.12.125

Murugesan, A., Vidhyadevi, T., Kalaivani, S. S., Thiruvengadaravi, K. V., Ravikumar, L., Anuradha, C. D., et al. (2014). Modelling of lead(II) ion adsorption onto poly(thiourea imine) functionalized chelating resin using response surface methodology (RSM). Journal of Water Process Engineering, 3, 132-143. http://dx.doi.org/10.1016/j.jwpe.2014.06.004

Naumov, S. (2009). Hysteresis phenomena in mesoporous materials. pp. 95.

Nilsson, C., Birnbaum, S., \& Nilsson, S. (2007). Use of nanoparticles in capillary and microchip electrochromatography. Journal of Chromatography A, 1168(1-2), 212-224. http://dx.doi.org/10.1016/j.chroma.2007.07.018, discussion 211

On the Experimental Attainment of Optimum Conditions on JSTOR (n.d.). Retrieved from http://www.jstor.org/stable/2983966?seq=1\#page_ scan_tab_contents. 
Paterakis, P. G., Korakianiti, E. S., Dallas, P. P., \& Rekkas, D. M. (2002). Evaluation and simultaneous optimization of some pellets characteristics using a 33 factorial design and the desirability function. International Journal of Pharmaceutics, 248(1-2), 51-60. http://dx.doi.org/10.1016/S0378-5173(02)00341-1

$\mathrm{Qu}$, J. (2008). Research progress of novel adsorption processes in water purification: A review. Journal of Environmental Sciences, 20(1), 1-13. http://dx.doi.org/10.1016/S1001-0742(08)60001-7

Raji-Asadabadi, M., Abolghasemi, H., Maragheh, M. G., \& Davoodi-Nasab, P. (2013). On the mean drop size of toluene/water dispersion in the presence of silica nanoparticles. Chemical Engineering Research and Design, 91(9), 1739-1747. http://dx.doi.org/10.1016/j.cherd.2013.03.011

Sadeghi Pouya, E., Abolghasemi, H., Assar, M., Hashemi, S. J., Salehpour, A., \& Foroughi-dahr, M. (2015a). Theoretical and experimental studies of benzoic acid batch adsorption dynamics using vermiculite-based adsorbent. Chemical Engineering Research and Design, 93, 800-811. http://dx.doi.org/10.1016/j.cherd.2014.07.016

Sadeghi Pouya, E., Abolghasemi, H., Esmaieli, M., Fatoorehchi, H., Hashemi, S. J., \& Salehpour, A. (2015b). Batch adsorptive removal of benzoic acid from aqueous solution onto modified natural vermiculite: Kinetic, isotherm and thermodynamic studies. Journal of Industrial and Engineering Chemistry, 31, 199-215. http://dx.doi.org/10.1016/j.jiec.2015.06.024

Sing, K. (2001). The use of nitrogen adsorption for the characterisation of porous materials. Colloids and Surfaces A: Physicochemical and Engineering Aspects, 187-188, 3-9. http://dx.doi.org/10.1016/S0927-7757(01)00612-4

Su, J., Lin, H., Wang, Q.-P., Xie, Z.-M., \& Chen, Z. (2011). Adsorption of phenol from aqueous solutions by organomontmorillonite. Desalination, 269(1-3), 163-169. http://dx.doi.org/10.1016/j.desal.2010.10.056

Sun, Y., Yan, F., Yang, W., \& Sun, C. (2006). Multilayered construction of glucose oxidase and silica nanoparticles on Au electrodes based on layer-by-layer covalent attachment. Biomaterials, 27(21), 4042-4049. http://dx.doi.org/10.1016/j.biomaterials.2006.03.014

Sun, Y., Yan, F., Yang, W., Zhao, S., Yang, W., \& Sun, C. (2007). Effect of silica nanoparticles with different sizes on the catalytic activity of glucose oxidase. Analytical and Bioanalytical Chemistry, 387(4), 1565-1572. http://dx.doi.org/10.1007/s00216-006-1013-1

Veilleux, J., \& Coulombe, S. (2011). A dispersion model of enhanced mass diffusion in nanofluids. Chemical Engineering Science, 66(11), 2377-2384. http://dx.doi.org/10.1016/j.ces.2011.02.053

Xin, X., Si, W., Yao, Z., Feng, R., Du, B., Yan, L., et al. (2011). Adsorption of benzoic acid from aqueous solution by three kinds of modified bentonites. Journal of Colloid and Interface Science, 359(2), 499-504. http://dx.doi.org/10.1016/j.jcis.2011.04.044

Yagub, M. T., Sen, T. K., Afroze, S., \& Ang, H. M. (2014). Dye and its removal from aqueous solution by adsorption: A review. Advances in Colloid and Interface Science, 209, 172-184. http://dx.doi.org/ 10.1016/j.cis.2014.04.002

Yan, L.-G., Wang, J., Yu, H.-Q., Wei, Q., Du, B., \& Shan, X.-Q. (2007). Adsorption of benzoic acid by CTAB exchanged montmorillonite. Applied Clay Science, 37(3-4), 226-230. http://dx.doi.org/10.1016/j.clay.2006.12. 014

Yıldız, N., Gönülşen, R., Koyuncu, H., \& Çalımlı, A. (2005). Adsorption of benzoic acid and hydroquinone by organically modified bentonites. Colloids and Surfaces A: Physicochemical and Engineering Aspects, 260(1-3), 87-94. http://dx.doi.org/10.1016/j.colsurfa.2005.03.006

Zachritz, W. H., Lundie, L. L., \& Wang, H. (1996). Benzoic acid degradation by small, pilot-scale artificial wetlands filter (AWF) systems. Ecological Engineering, 7(2), 105-116. http://dx.doi.org/10.1016/0925-8574(96)00003-1

Zhang, Z., Wang, Z., Liao, Y., \& Liu, H. (2006). Applications of nanomaterials in liquid chromatography: Opportunities for separation with high efficiency and selectivity. Journal of Separation Science, 29(12), 1872-1878. http://dx.doi.org/10.1002/jssc.200600154

Zhong, K., \& Wang, Q. (2010). Optimization of ultrasonic extraction of polysaccharides from dried longan pulp using response surface methodology. Carbohydrate Polymers, 80(1), 19-25. http://dx.doi.org/10.1016/ j.carbpol.2009.10.066 